\title{
(2) \\ Rosas transplantadas y el mito de Eldorado. Travesías en el tiempo, en el espacio, en la imágen y en el silencio
}

\section{RMA}

Antropología Social
Elizabeth Jelin

CONICET - IDES. E-mail: elijelin@fibertel.com.ar

\begin{abstract}
Resumen
El punto de mira está en Eldorado, Misiones, alrededor de 1920. Voy a seguir algunas líneas de su historia en las tres décadas siguientes, una historia que puede ser leída como el arribo de la "civilización", la modernidad y el progreso a una tierra salvaje, indómita. La ruta clave para esto fue la de la inmigración europea, en parte desplazada por la pobreza, el conflicto y la destrucción. Del otro lado estaba el atractivo de un futuro dorado de riqueza y felicidad. La "localidad" y lo "local" -en este caso al igual que en otros- no es lo que quedó fuera del centro. Más bien, es un pedazo de un mundo interrelacionado. La tarea que propongo surge de intentar conceptualizar lo "local" no en contraste con lo "global" o lo "macro" sino como un "centro descentrado" desde el cual se puede mirar el resto del mundo, una base desde la cual se pueden establecer o romper (también criticar, desear, formar y transformar) redes y conexiones con otros lugares, otras gentes y otras instituciones. Desde este centro descentrado, la historia de Europa no es la de un lugar sino la de flujos y redes, de personas y de vínculos políticos e institucionales, de intereses económicos y de lazos personales y familiares. Las cartas y las fotografías mandadas y recibidas, las autobiografías, los relatos familiares y los álbumes de fotos son los medios para explorar estos flujos. Están también los documentos públicos más convencionales y los periódicos impresos. Todo esto es lo dicho; también hay muchos silencios que deben ser develados.

El caso de Eldorado será usado para plantear algunas reflexiones y preguntas sobre temas más generales de la investigación social: la conceptualización de la relación entre lo local y lo global, entre centro y periferia; la separación entre lo privado y lo público; la divisoria que establecemos entre racionalidad y objetividad por un lado, y las pasiones y emociones por el otro; el vínculo entre la investigación académica y los compromisos intelectuales; quizás algo sobre circunstancias y coincidencias en los procesos de plantear preguntas de investigación.
\end{abstract}

Palabras claves: Eldorado, Misiones, local-global, nazismo, familia, inmigración, investigación social reflexiva.

Translocated roses or the myth of Eldorado: Journeys through time, space, image and silence

\begin{abstract}
The looking glass is directed towards Eldorado, a virgin subtropical land in Northeastern Argentina, around 1920. I will be following some lines of its history during the following three decades, a history that can be read in terms of bringing "civilization", modernity and progress to an untamed savage land. The basic route was that of European immigration, in part escaping from poverty, conflict and destruction.

The "locality" and the "local" -in this case as in others-are not what is left over or kept out of the center. Rather, it is part of an interrelated world. The task I propose stems from an attempt to conceptualize the "local" not in contrast to the "global" or the "macro" but rather as a shifted center from which the world can be looked at, a base from which webs of connections with other places, peoples and institutions are made and broken, shaped and reshaped. From this "descentered" center, the history of "Europe" becomes not a history of place but one of flows and webs --of people or of political and institutional links, of economic interests, of personal and family ties. Personal letters and photographs sent and received, auto- and family biographies and the photo album are the means to explore such flows. There are also the more conventional public documents and printed newspapers. It is also a story of many silences to be uncovered.

The case of Eldorado will be used to reflect upon and pose some questions about more general issues in social research: the conceptualization of local-global and center-periphery relationships; the private-public divide; the split we construct between rationality and objectivity on the one hand, and passions and emotions on the other; the "embodied" link between academic research, intellectual commitments and the public sphere; perhaps something about chance and choice in asking research questions.
\end{abstract}

Keywords: Eldorado, Misiones, local-global, Nazism, Family, immigration, investigación social reflexiva 


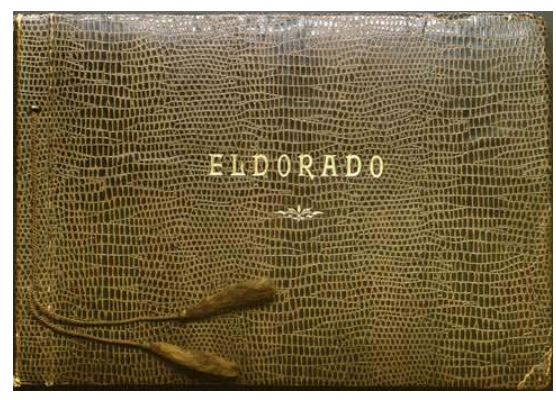

Eldorado, Diciembre 1 de 1930

Esther...

Estoy ahora en la colonia Eldorado, a dos días de viaje en barco desde Posadas. Se viaja por el río Paraná, que es la frontera entre Argentina, Paraguay y Brasil. Es uno de los lugares más lindos de estos países, porque está en el medio de los bosques tropicales. También está cerca de las cataratas del Iguazú, donde llegan turistas de todo el mundo.

Llegar aquí y pensar en todo lo que ocurrió es realmente para maravillarse. Hubo gente que se dedicó y transformó estos lugares, que estaban todos sobrecrecidos e invadidos de vegetación, con árboles altos hasta el cielo, tan denso que no se puede meter ni un alfiler. Gente que no estaba acostumbrada a las condiciones climáticas y se las arreglaron para trabajar con más de 40 grados, con lluvias que caen a chorros, como ocurre en las zonas tropicales. Un lugar lleno de animales salvajes y pájaros, con tantas dificultades que no me es posible contar o describir; y agarraron un lugar así e hicieron un verdadero Jardín del Edén, donde se vive una vida tranquila, con las mejores condiciones técnicas y con buenas condiciones climáticas, saludables. Todo lo demás es selva y cerros... Todo esto lo hicieron los alemanes. Es para asombrarse ver qué pueblo de trabajadores voluntariosos! ¡Cuánto esfuerzo humano les Ilevó!

Todo esto fue hecho por los inmigrantes, de los que cinco mil son alemanes. Ahora se ocupan de la madera, hay muchos aserraderos; también hay plantaciones de tabaco y "yerba". Esta es la bebida nacional de los países de América del Sur. Se lo toma de la siguiente manera: después de picar las hojas [secas], se las echa en una especie de cajita, un recipiente que es la parte de afuera donde había crecido una fruta. La cajita tiene el aspecto de madera. Se le echa agua caliente pero no hirviendo, y con un tubo largo se chupa el agua. Es una sensación muy linda ver a la gente sentada por la noche, alrededor de un fuego, y el recipiente pasa de mano en mano, y todos chupan del mismo tubo ... También crece aquí la pimienta, y si se dice "escaparse adonde crece la pimienta", eso es exactamente aquí!

Samuel iba a cumplir diecinueve años un par de semanas después de escribir esta carta a una amiga que quedó en Europa Central.

Estamos en Eldorado. ¿Qué es, o era, Eldorado? Según
Wikipedia, la palabra refiere a una leyenda acerca de un lugar mítico donde había tanto oro que se lo llegaba despreciar. La leyenda dice que al cacique del lugar se lo cubría con polvo de oro para ceremonias en un lago. Hay informes sobre esta leyenda ya en 1530, en la zona de Boyacá cercana a Bogotá, Colombia. La leyenda viajó a los pueblos de los colonizadores españoles, y de ahí a España, donde la imaginación transformó a Eldorado en un reino, en un imperio, en una ciudad con un legendario dios dorado. Muchos conquistadores siguieron senderos insospechados para llegar a la ciudad del oro.

El mito y la metáfora aparecen y reaparecen en la literatura y en el cine, desde Milton hasta Edgar Allan Poe, desde John Wayne (recitando el poema de Poe en su película de 1966) hasta "Aguirre, la ira de Dios", película de Werner Herzog. La lista puede seguir con el Pato Donald en su viaje por el Amazonas, y según Wikipedia, la leyenda de Eldorado figura en la reciente película "Indiana Jones y el reino de la calavera de cristal".

Volvamos a la realidad. Eldorado es hoy en día una ciudad de unos 70.000 habitantes, en la ribera este del río Paraná, a 100 km. de las Cataratas del Iguazú y a 200 km. de la capital de la provincia de Misiones, Posadas, en la frontera entre Argentina y Paraguay.

La "historia" de la zona en este caso, en el sentido occidental de historia escrita- se remonta a las misiones jesuíticas del siglo diecisiete, cuyas ruinas son hoy un sitio declarado por la UNESCO en sus marcas de la "Herencia de la Humanidad". El nombre de la provincia viene de las Misiones (esta vez la película es inglesa, con Robert de Niro y Jeremy Irons).

Adolfo Julius Schwelm era un ciudadano británico, aunque nacido en Alemania (era un judío converso, práctica muy habitual en la época). Llegó a Buenos Aires en 1915, enviado por la Banca Rotschild. En 1918, Schwelm compró en un remate una fracción de tierra de 67.000 hectáreas en el territorio de Misiones. Las escrituras de propiedad definen el área como la comprendida entre los arroyos Piray Guazú y Piray Miní. Su idea era vender las tierras, en parcelas de entre 25 y 50 hectáreas, a colonos europeos, en lo que se conocía en la época como modelo de colonización privada. Según algunas historias locales muy idealizadoras o románticas, Adolfo Schwelm se sintió cautivado por la zona cuando fue a visitar las Cataratas del Iguazú a comienzos de $1918 .^{1}$

\footnotetext{
1 "Así fui remontando el Paraná días y días. Me embelesaba esa cortina interminable que festoneaba caprichosamente la costa a modo de un gigantesco telón ocultando celosamente cuanto podía haber detrás. A medida que subía, el Paraná se iba encajonando y al mismo tiempo se angostaba cada vez más. Mi imaginación comenzó a dar vueltas en torno a ese extraño mundo que contemplaban mis ojos. Sentí su poderosa atracción... Ordené fondear frente a los cerros. Me puse a observar, no sé por qué, atentamente el lugar, y quedé en silencio: fue entonces que allí me asaltó una idea. ¡Qué extraordinario sería poblar esto, colonizarlo!" (citado en Arenhart de Romagosa 2003, p. 159).
} 
El 29 de septiembre de 1919 a las 10 de la mañana, cuentan las historias locales, desembarcó en las playas arenosas de lo que iría a convertirse en el puerto de Eldorado. La fecha de llegada fue cuidadosamente elegida: era el día de su cumpleaños, pero también el día de San Miguel Arcángel, patrono de Alemania. Elegir una fecha fundacional con fuerte significación fue parte de su estrategia de construcción de una futura identidad comunitaria (quienes estudiamos procesos de memoria sabemos que la política de la memoria y de la conmemoración futura se inicia en el momento mismo en que un acontecimiento importante ocurre, a menudo con libretos ya preparados para el sentido que sus emprendedores quieren dar a las conmemoraciones futuras. En este caso, el 29 de septiembre se convirtió en la fecha de celebración anual de la fundación y la identidad de Eldorado). Obviamente, el nombre de la colonia hacía referencia a la leyenda, "el paraíso terrenal, donde se hallan cuantiosas riquezas y tesoros..." (Rizzo 1987, p. 22), "paraíso salvaje de tierra colorada y selva virgen" (Micolis 1973, p. 11). Hay historias alternativas que encuentran el origen del nombre en la pasión de Schwelm por la pesca y el nombre del pez más común en la zona, el dorado.

Schwelm llegó en su barco, el "Svástica", acompañado por otro barco, el "Cuñataí" ("joven mujer" en Guaraní). Durante un tiempo, vivió en el barco cuando estaba en la colonia, hasta que hizo desarmar su casa de madera en el Chaco y la trasladó a Eldorado, para reconstruirla en un terreno cercano al muelle, en lo que después sería un parque con su nombre (¿recuerdan "Fitzcarraldo" de W. Herzog?).

No voy a entrar en los detalles de la historia de la colonización en Argentina, o más específicamente la colonización en Misiones. Eldorado es mi punto de referencia, y trataré de trabajar a partir de allí. Lo que quiero es tomar esta localidad como un "centro descentrado" (tomando la expresión de una comunicación de Rosalind Shaw) desde el cual se puede mirar el resto del mundo, una base desde la cual se pueden establecer o romper (también criticar, desear, formar y transformar) redes y conexiones con otros lugares, otras gentes y otras instituciones. El objetivo es explorar si en este tipo de análisis, es posible avanzar evitando establecer jerarquías de lugares, centros y periferias.

Ésta es el punto de partida que elijo para esta historia. Después de desembarcar y de explorar los alrededores del lugar, Schwelm y sus acompañantes marcaron el lugar con una estaca con la marca "Km 0", y a partir de ella iniciaron el diseño del camino central de la colonia, la Picada Maestra, que iba del oeste hacia el este. El diseño de la colonia se basó en un modelo medieval alemán, adecuado para zonas montañosas con bosques, el Waldhufendorf ("aldea que se extiende en una franja angosta del bosque"), que contrasta con el modelo del damero (Arenhartdt de Romagosa 2005, Eidt 1971). El hecho es que desde entonces y hasta ahora, la ciudad tiene ese camino central; los lugares se referencian por el Km. medido en términos de la distancia desde el puerto en el río Paraná. El diseño es de núcleos de población sucesivos, con picadas transversales, algunos más importantes que otros -Km 2, Km 9, Km 14, etc. La Picada Maestra tiene unos $30 \mathrm{~km}$ de longitud.

Schwelm desarrolló una importante campaña publicitaria para atraer pobladores. Tenía sus propias ideas y toda una filosofía acerca de la colonización, tema sobre el cual escribía, daba conferencias en Europa y figuraba en numerosas entrevistas en medios gráficos. Promocionaba a Eldorado personalmente y a través de sus oficinas en Londres, Berlín y París, a través de folletos y películas documentales. Inclusive hay quien sostiene que la Argentina se conocía en el norte de Europa a través de la propaganda de Eldorado. El foco puesto en la inmigración desde el norte de Europa era explícito: "Mis preferencias a este respecto se inclinaron hacia las razas nórdicas. Los primeros colonos de Eldorado fueron alemanes, dinamarqueses, suecos. Ellos constituyen actualmente -hablaba en 1931- la mayoría de la población. Hay también un puñado de británicos, austríacos y húngaros" (citado en Rizzo 1987, p. 37). En esa época -que es aproximadamente cuando M. escribía su carta- Eldorado, con aproximadamente 7.000 habitantes, era de hecho una colonia con cultura y lengua alemana.

La pregunta que surge inmediatamente es, ¿por qué el menosprecio de los inmigrantes mediterráneos? Era una cuestión de preferencias personales, que se ajustaban muy bien a las imágenes prevalecientes en las elites argentinas, siempre listas a exaltar las virtudes de esas razas "nórdicas".

Su propaganda (en alemán) decía: "Invitamos a todos aquellos que las circunstancias llevan a buscar un futuro seguro: aquellos que, lejos de renunciar a la cultura de su país de origen, están dispuestos a trasplantarla a su nueva patria, a aquellos que consideran su felicidad y placer en la adquisición del confort y la riqueza por medio de un trabajo perseverante y una voluntad sólida" (Rizzo 1987, p. 38). En 1924, los folletos ya mencionaban que Eldorado tenía electricidad, agua corriente, comercios, una escuela alemana para enseñar el idioma a los chicos, y otras comodidades. Parecía que en el marco de una naturaleza salvaje, estaba asegurado el mantenimiento de una forma de vida "civilizada". A lo largo de los años, además, hubo muchos visitantes europeos importantes que llegaron a Eldorado: desde un príncipe prusiano y la princesa Cecilia hasta embajadores y figuras de la nobleza. Sus visitas eran registradas y utilizadas en las campañas publicitarias.

Los primeros colonos llegaron en 1920. Hay distintas versiones acerca de quiénes fueron "los primeros". En realidad, es fascinante leer en diversas historias y registros locales, en los escritos biográficos de pioneros y sus descendientes, las permanentes alusiones y marcaciones 


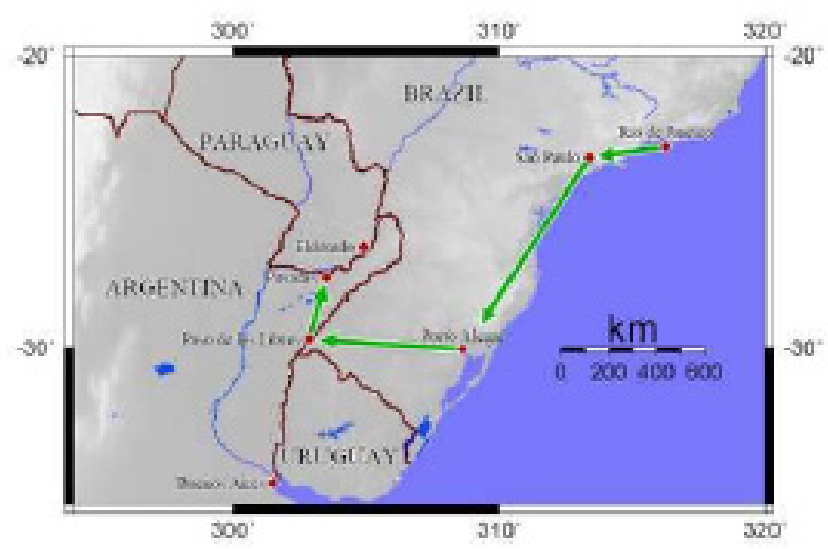

de la distinción implícita en ser el primero: "el primer" nacimiento, casamiento, muerte, la primera casa, el primer cura y la primera misa, el primer maestro... La información es bastante diversa y contradictoria. Para evitar conflictos, diré que "entre" los primeros colonos había daneses reclutados en Buenos Aires y alemanes que venían de Rio Grande do Sul (Brasil). Éstos últimos eran descendientes de inmigrantes alemanes que se habían establecido en el sur de Brasil en la primera mitad del siglo XIX. En su camino hacia Eldorado, viajaron por el mismo camino que $\mathrm{M}$. haría diez años después: por tierra hasta Paso de los Libres, el tren hasta Posadas y de allí el barco. Los primeros colonos que vinieron directamente desde Europa llegaron en 1922. Eran alemanes y daneses. En 1924 había 60 familias en la colonia.

Dada la llegada de sucesivas olas de inmigrantes de diferentes orígenes, Don Adolfo decidió organizar la colonia. Esto significó distribuir la población de acuerdo con criterios identitarios, fundamentalmente el lugar de origen y la lengua hablada. Surgen entonces asentamientos diferenciados a lo largo de la Picada Maestra: la "picada danesa" (entre el puerto y el km. 9); la picada de lo bávaros católicos o "Bayernthal" en el km. 24; el "Schoenthal" donde predominan alemanes de origen polaco; la "picada suiza" en el km. 28, la "picada Wurtemberg" con alemanes de Alemania en el km. 18. Los alemanes brasileños se dispersan en varios lugares (Arenhardt the Romagosa 2005, p. 16, entre otros).

En 1929, el Sr. Schwelm podía presentar a Eldorado como el mito hecho realidad -al menos en su álbum de fotografías. A continuación van algunas de sus páginas. ${ }^{2}$

Sin embargo, como podría esperarse, el sentimiento de desilusión fue muy común al llegar. Muchos quisieron irse, pero habían usado todos sus ahorros para comprar la tierra, de modo que tenían que quedarse... Los informes familiares y las autobiografías, escritas mucho después, glorifican el heroísmo de los pioneros, que tuvieron que

2 El álbum es parte de una de las Colecciones Especiales del Instituto Iberoamericano de Berlín. La directora y los funcionarios del Instituto ayudaron al proyecto proporcionando una versión digitalizada del álbum y prestando el original para la presentación oral en el coloquio del Wissenschaftskolleg. superar todos los obstáculos, desde el calor y la humedad tropical, las copiosas lluvias y los caminos y puentes inexistentes, hasta los mosquitos y los imbarigües, con la certeza de que Eldorado no existía sino que debía ser construido, sin el dinero para poder escapar...

En las varias historias familiares que leí sobre los años iniciales de la colonia, hay un silencio muy notorio: casi no hay "otros" aparte de los colonos del Norte de Europa. Los argentinos parecen no haber tenido ningún papel. Todos los lugares o roles públicos estaban en manos de los colonos de origen europeo o del personal de la compañía colonizadora. En verdad, los europeos consideraban a Eldorado como su pueblo, y los demás eran vistos como "extranjeros". Poco y nada se dice acerca de las poblaciones del lugar. En textos más históricos hay referencias ocasionales a "los paraguayos" (Rizzo 1987, p. 44), o sea a la población guaraní. Sin embargo, sabemos que estos "oscuros y misteriosas gentes de la selva" -así expresado en uno de estos informes- trabajaban para los colonos, ofreciendo la mano de obra más barata posible. Son ellos quienes estaban a cargo de las tareas más pesadas, centralmente las del desmonte.

La distancia cultural entre patrones y peones era en realidad un abismo. Los colonos tenían una idea bien clara de los hábitos de los "paraguayos": vivir al día, no pensar en el futuro, inestabilidad social. Los "paraguayos" no eran una amenaza, porque las relaciones eran clara y explícitamente jerárquicas. Los alemanes y los guaraníes pertenecían a dos mundos diferentes y separados. Los peones paraguayos eran "Hiesigen", y con esto bastaba. Eran parte de la naturaleza, que estaban en el lugar desde los orígenes del tiempo, dispuestos a luchar en contra de la selva. Si miramos nuevamente la carta de M., quienes toman mate alrededor del fuego no son los colonos alemanes...

Este silencio contrasta con la importante presencia de la figura del "mensú" en la historia y la imaginación argentinas y paraguayas. Se trataba de un sistema de trabajo semi-servil, y su nombre proviene del modo de "pago" mensual, pago en vales y no en dinero. En las representaciones en el cine y la literatura, la figura del mensú y la localización en la zona de las misiones son numerosas, en

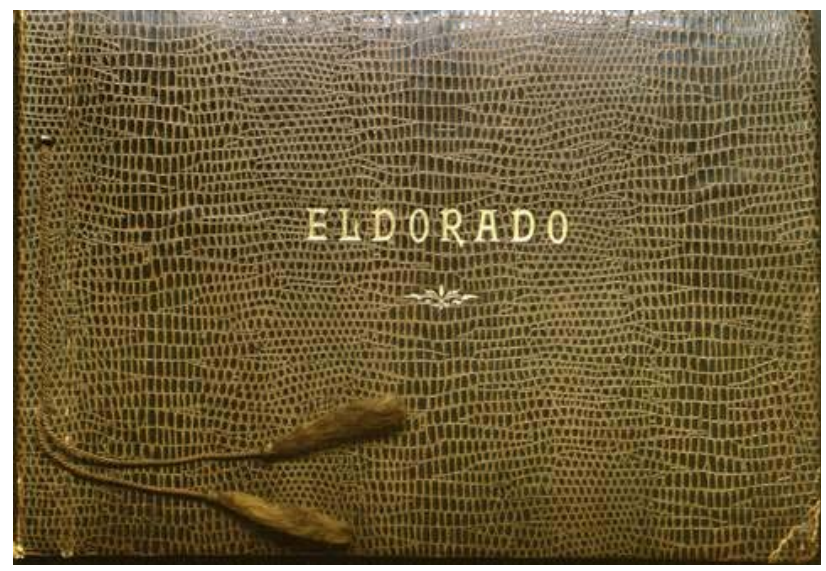



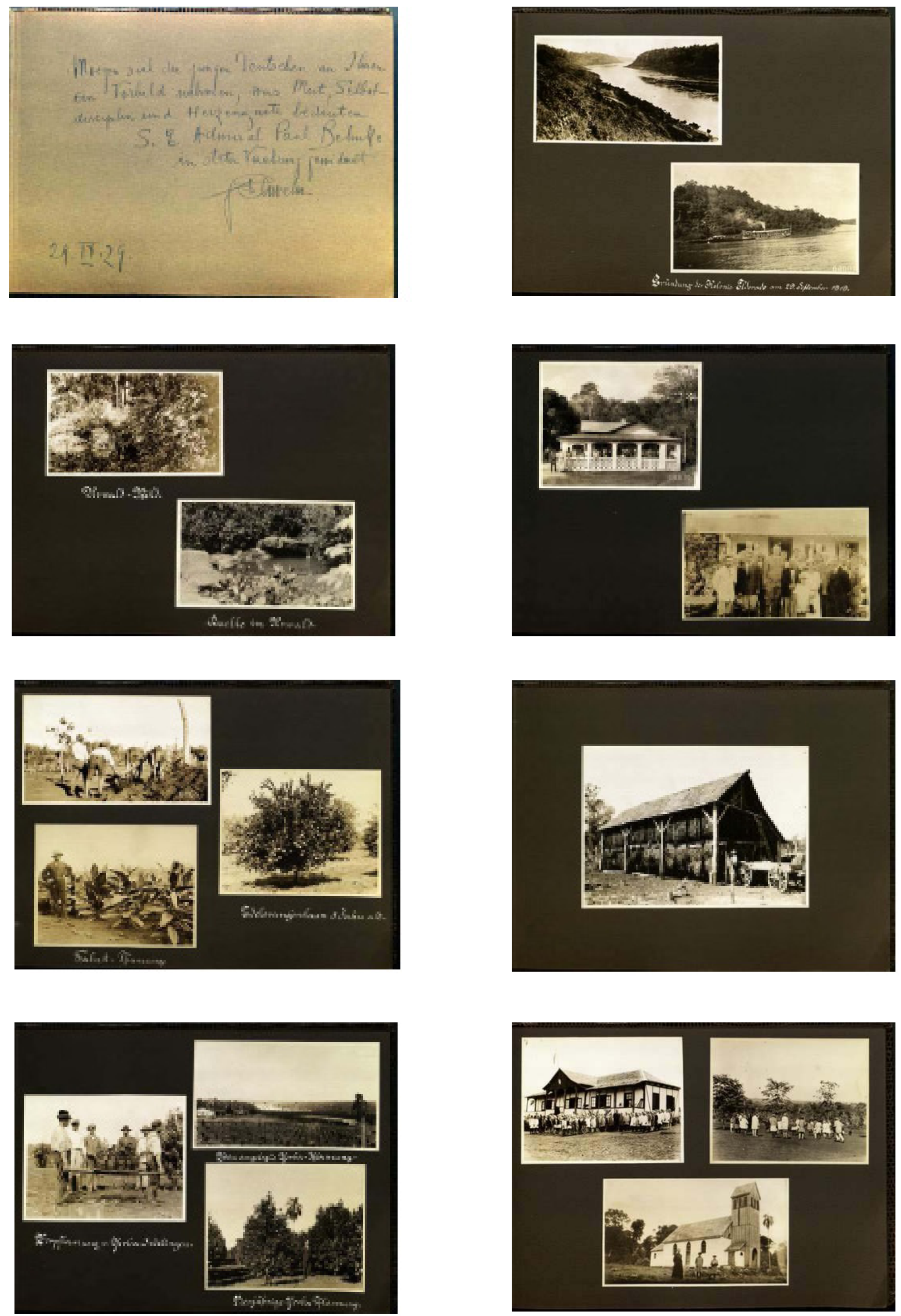

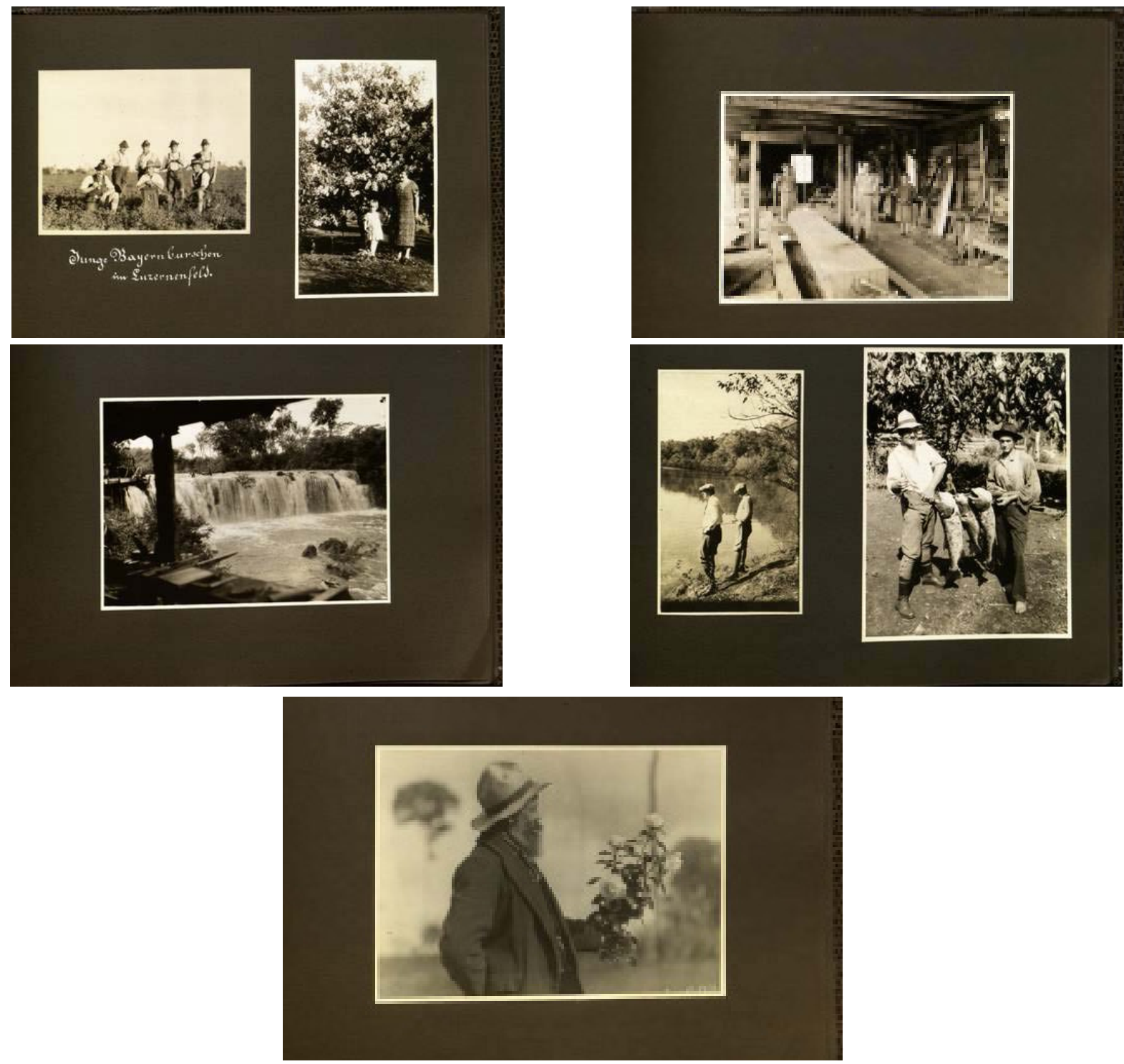

los cuentos de Horacio Quiroga y en textos de Roa Bastos. También en el cine: "Las aguas bajan turbias" (Hugo del Carril, 1952), "El trueno en las hojas" (Armando Bo, 1958), y "Prisioneros de la tierra" (Mario Soffici, 1939). Por supuesto, también la figura está presente en la música, especialmente en el Chamamé.

Hay otros silencios en lo que leo. No se menciona a los argentinos. No se menciona a los comerciantes judíos o libaneses, sea los instalados o los itinerantes. Sin embargo, existían...

Sigo leyendo cartas escritas a lo largo de los dos años siguientes. Quiero encontrar más descripciones de Eldorado, pero son muy escasas. Hay referencias a la lluvia, al silencio y a la soledad. También el relato de un accidente, al tratar de poner en marcha una "chatita" con la palanca. La mayor parte del espacio de las cartas está dedicado al tema de la carta misma -que no contestaste enseguida, que escribí a tal o cual, que si escribo cartas cortas o largas, que si el papel es más grande aquí o allí, o a quién dar a leer o de quién ocultar algo de lo que se escribe. También se describen los momentos en que se escribe: "Domingo por la noche, está lloviendo, estoy sentado en la cama y en una mesita al lado de la cama, me pongo a escribirte" y cosas por el estilo. Como si la urgencia estuviera en hacerse presente en la ausencia, en mostrar que uno está presente aunque no esté en el lugar. Voy a encontrar este mismo patrón de cartas "vacías" de información diez años después, en momentos en que M. está en Eldorado y su esposa en Buenos Aires. Cartas escritas día por medio, que no dicen prácticamente nada, excepto "Aquí estoy".

Me pregunto sobre los cambios que los desarrollos de las tecnologías de la comunicación provocan sobre la subjetividad de la presencia/ausencia. Imagino que hay mucha investigación sobre el tema, sobre el efecto del correo electrónico e internet, mensajes de texto y teléfonos celulares, conexiones permanentes en tiempo "real", desterritorializadas y al mismo tiempo siempre estructuradas por el tiempo y el espacio (la pregunta "¿dónde estás?" es siempre la primera pregunta cuando se habla por teléfono celular...). Me pregunto si estos estudios 
incorporan una perspectiva histórica, donde los tiempos y las distancias eran otros.

Y se dice mucho sobre fotografías: uno pide a la otra que mande alguna; se cuenta que aunque se tiene cámara, no se consiguió rollo; que se demora el revelado porque en el laboratorio no recibieron papel o químicos; acerca de cuántas fotos se mandaron en cartas anteriores; acerca de las dificultades de tener una foto retrato de la persona sola y cómo debe ser reemplazado por el envío de fotos grupales como substituto de "segunda clase". Es claro aquí lo que Marianne Hirsch tiene que decir sobre el lugar de las fotografías:

...in lives shaped by exile, emigration and relocation, where relatives are dispersed and relationships shattered, photographs provide perhaps even more than usual some illusion of continuity over time and space... Family pictures depend on such a narrative act of adoption that transforms rectangular pieces of cardboard into telling details connecting lives and stories across continents and generations (Hirsch 2002, p. xi-xii).

Volvamos a Eldorado, ahora en 1930. Los informes escritos, con la excepción de alguno de corte más académico, evitan mencionar conflictos humanos. Como en toda sociedad o comunidad, sin duda los había. En términos económicos, los procesos de comercialización siempre están llenos de tensiones y disputas. Inicialmente, la comercialización del "oro verde" (la yerba, pero también el tabaco, la madera y el tung después) estaba en manos de intermediarios. En 1931, la salida a las disputas de precios fue crear una cooperativa.

Las diferencias religiosas y étnicas también dividían a la colonia. Registré varios conflictos alrededor de las iglesias y las escuelas, entre y dentro de las comunidades luterana y católica. Entre los luteranos, por ejemplo, a comienzos de los años treinta hubo una división entre los alemanes alemanes (los "Reichdeutschen") que construyeron su escuela e iglesia en el km. 14, y el resto-los dinamarqueses y los "Schoental" de origen polaco-que lo hicieron en otro lado.

Entre los católicos, las divisiones eran entre los alemanes brasileños ("Deutschbrasilianer") y los de Bavaria. El grupo bávaro estaba compuesto por una docena de familias que llegaron con su propio cura, provenientes de un solo pueblo, Turkenfeld. Llegaron al Chaco en 1925; allí los encontró Schwelm y les propuso su traslado a Eldorado, debido a las sequías en el Chaco. Se los conocía como "Die Chaco Leute". Se establecieron en la picada Bayernthal, en el km. 24. El cura debía dividir su tiempo en las dos comunidades, y pronto, los bávaros se fueron independizando. Los bávaros también organizaron su coro y grupo de danzas, el "Sangverein Germania".
Llegamos a 1935. Las asociaciones alemanas intensificaron sus actividades. Más que nunca, los alemanes se aferraron a sus tradiciones y a la admiración por la patria. Gradualmente, y con el apoyo de la embajada alemana en Buenos Aires y el consulado en Posadas, muchos se volvieron entusiastas adherentes a la Alemania de Hitler. La escuela alemana más importante de Eldorado, fundada en 1926, jugó un papel central en la transmisión de los sentimientos pro alemanes. Para dar un ejemplo: un maestro de castellano, que llegó a trabajar a esa escuela en 1938, señala que se sorprendió al ver que los niños formados, al cantar el himno alemán, lo hacían con el brazo extendido del saludo nazi (Rizzo 1987, p. 99).

En verdad, entre 1935 y 1945, la escuela, el club deportivo alemán y la organización de los "Deutschjungen" -que seguía el formato del movimiento juvenil Nazi ("Hitlerjugend") - tuvieron un papel ideológico central. Había reuniones semanales en las que se pasaban documentales sobre los avances alemanes en la guerra. Veinte colonos volvieron a Alemania como voluntarios para la guerra. Se hablaba del final victorioso de la guerra y de las opciones: quizás expropiar las tierras de los anti-Nazis (en la zona de Eldorado) y ofrecerlas al Führer para reubicar allí a los judíos desplazados (esto antes de la "Solución final"); ofrecerse como voluntarios para ocupar los territorios de Ucrania y Rusia, como parte de la política de arianización. La central del partido Nazi de Eldorado se llamaba "Das Braune Haus".

Todo esto implicaba cambios muy significativos. Después de años dedicados a la lucha en contra de la naturaleza, los alemanes (todavía divididos en los varios grupos según su origen) empezaron a dedicarse a temas políticos y sociales. La Alemania Nazi exaltaba la identidad, la raza y la etnicidad. Sus sentimientos los llevaban a pedir una independencia total con relación a la Argentina.

De todo esto, no se habla en los relatos de la zona. Años después, el silencio histórico es casi total... Los pocos testimonios que existen (recogidos por una investigadora a fines de los años 60 , para una tesis a ser presentada en francés en una universidad canadiense), tienden a ser de quienes se opusieron al nazismo. Dos testimonios:

Para 98\% de los alemanes de Eldorado, las ideas de la conquista mundial, del poder y la gloria, del reinado universal de Alemania durante los próximos mil años -todo esto era como entrar en una vorágine y bailar sin parar. Éramos un grupo muy pequeño de católicos que nos negamos a entrar en ese juego; en términos económicos éramos sistemáticamente boicoteados por nuestros propios compatriotas. ... Había discusiones muy violentas entre los alemanes. De esta manera y sin tener total conciencia de lo que pasaba, los colonos se embarcaron en una operación suicida (Micolis 1973: 33). 
Vivíamos en un aislamiento más difícil de sobrellevar que el aislamiento geográfico de los primeros años de la colonización. Nuestra lucha en contra del Hitlerismo demandaba mucho más que la lucha contra la naturaleza. Porque contra la naturaleza luchábamos todos juntos, mientras que durante el Hitlerismo teníamos que luchar contra nuestros compatriotas. Es mucho más duro luchar contra el salvajismo y el barbarismo del hombre extremista y fanático (Micolis 1973: 35).

También hay un testimonio de un colono inglés de Victoria, un asentamiento cercano:

Cuando empezaron a aparecer las nubes de la Segunda Guerra Mundial, nuestras actividades se intensificaron, y la sala grande se empezó a usar para bailes y rifas, a los que invitábamos a algunos miembros de la comunidad alemana de la vecina Eldorado; un buen número de ellos eran anti-Nazis... Lo que recaudábamos lo mandábamos a la Cruz Roja Británica a través del Banco de Londres y América del Sur, de Buenos Aires. En los meses posteriores a la entrada de Gran Bretaña a la guerra, la mayoría de los colonos británicos en edad militar se volvieron a la patria como voluntarios (Cooper 1986: 120).

En 1939, Adolfo Schwelm renunció como Presidente de la Compañía Colonizadora. Estaba dolido y molesto por la orientación que sus colonos habían tomado. La visión romantizada de su vida y su destino continúa diciendo que "veinte años después de la fundación de la colonia, sintió que Eldorado escapaba de sus expectativas y de su poder moral. Schwelm se 'exiló' en su casa y en su jardín, en soledad. La selva fue invadiendo sus 20 hectáreas de pasto inglés, y murió allí en 1948, sólo y en bancarrota." (¿?). Otros piensan de distinta manera y lo pintan como mentiroso, autoritario y arbitrario...

Leo ahora cartas de 1937 y 1938, época en que después de muchos años de estar separados, Samuel y Esther estaban haciendo planes y trámites para el viaje de Esther a Argentina.

\section{Eldorado, 18/IX/37 \\ Mi queridísima!}

...

¡Cómo querría complacerte y viajar a Amdur! ese Amdur al que uno está tan atado. Ese lugar que no se puede olvidar, porque ¿cómo se va a olvidar el lugar donde uno nació y creció?, ¿donde pasó los años de la infancia?, ¿donde cada rinconcito hace recordar las experiencias vividas? Y no solamente eso, sino el poder estar junto a vos, a papá y mamá. No se trata de una cuestión económica sino de tiempo, y lo más importante, "Polonia, Europa". iCon cuánto odio se dice aquí la palabra "Polonia"!, un lugar de sufrimiento y barbarismo, y "Europa", la Europa que está parada en el umbral de una ruptura fundamental, que puede derivar en otra guerra. Y quizás uno sacrifica su vida, pero ¿para quién? Para que otros se beneficien de esto. Quizás nosotros podemos pensar la situación objetivamente, y ver mejor que ustedes, que están allá.

Y la respuesta,

\section{Grodno, 30/X/37}

... Estuve en Amdur. Decís que extrañás, pero todo está igual, las mismas hojas. Todo está oscuro, y quizás más oscuro que antes, pero igual seguimos adelante, vamos donde tenemos que ir, salimos de casa cuando se necesita.

A esa altura, las condiciones de emigración e inmigración habían cambiado. En 1930, M. obtuvo su pasaporte en febrero, dejó Polonia por tren y se embarcó en Génova el 12 de marzo (hay una carta desde Génova, contando el viaje en tren a través de Austria). Llegó a Río el 26, estuvo en Porto Alegre el 3 de abril, y cruzó la frontera argentina el 16 de abril. Todo en dos meses. Ahora, el papelerío para el viaje de E. empezó antes de octubre de 1937, y para cuando tuvo el pasaporte, en julio de 1938, tuvo que estar semanas en Varsovia para conseguir la visa argentina. Las cartas lo dicen todo:

\section{Varsovia, 2/VIII/38}

Mi querido,

Al fin llegó el día en que todo está listo, el día de mi partida, el día en que me tengo que despedir de mis queridos amigos, conocidos, cercanos, con todo y con todos! ¡Ya estoy tan lejos de ellos! Estoy en Varsovia en el hotel de emigrantes. Es el sexto día. Nuestro transporte debió haber partido a la mañana siguiente de nuestra llegada a Varsovia, pero el cónsul argentino achicó la cantidad de visas que entrega. En vez de dar 40 visas por día entrega solamente 5-6. Desde hoy va a otorgar 15. Por eso tuvimos que suspender el viaje y nuestro barco partió con muy pocos emigrantes. Ahora tenemos que esperar que salga otro barco, y esto será el 10/VIII. Aunque no tenemos visas, nos aseguraron que viajaremos en ese barco. Si no conseguimos las visas aquí, nos van a mandar a Londres y allí nos van a dar visas como para poder seguir viaje. Ya hubo un caso similar antes de mi llegada, y viajaron con un transporte así.

$\cdots$

escribo todo esto sobre mi, yéndome tan lejos. No lo puedo creer. No siento nada, no extraño nada ni a nadie, lo que quiero es que estas semanas pasen rápido. Todavía faltan cinco semanas; 
quizás algo menos. El barco llega a Argentina el 9/IX, y aquí los días son tan largos, se estiran, el tiempo pasa tan lento...

$\cdots$

Esther

Me acaban de traer fotografías, pero no las pongo en esta carta.

$P S$. El barco con el que voy a viajar se llama "Almanzara" y llega a Argentina el 9/IX.

Y la última carta de este tipo:

Varsovia, 19/VIII-38,

Como ves, todavía estoy en Varsovia, en el hotel de emigrantes, por la cuarta semana. Te mandé una carta por vía aérea diciendo que íbamos a salir con el Almanzara, pero ... el cónsul decidió no otorgar ninguna visa, y cuando llegó el momento de partir, el transporte salió con sólo cuatro emigrantes del hotel... ¿Podés imaginarte? Hay cien personas en el Hotel. La situación es desesperante. La gente se enferma por la preocupación y la angustia. Estás sentada y no hay esperanzas de conseguir una visa. Uno podría pensar en volverse a casa, pero hay familias que vendieron todo y están en bancarrota, y no tienen dónde volver. La gente va varias veces al día a las oficinas de la compañía de barcos, al sindicato, y nadie tiene una respuesta. Nos aseguran que están tratando de resolver la situación. Nadie puede contestar a la pregunta de por qué el cónsul dejó de otorgar visas. Hay rumores de que no quiere dejar entrar a los judíos al país. ...

De pronto, la carta cambia, como si hubiera interrumpido por algo para seguir después:

El viernes pasado recibimos un aviso del sindicato diciendo que dos chicos, que viajaban para encontrarse con su padre, tienen que ir al consulado para recibir sus visas. Yo tuve una idea feliz: voy a ver si tengo suerte; voy a ir con ellos a ver al cónsul... Tuvimos que esperar bastante hasta que los chicos entraron a la oficina. Después de 10 o 15 minutos, salieron felices porque les habían dado las visas. Yo me levanto, sin esperanzas de conseguir nada. Me quedo parada junto a la puerta; todo mi cuerpo tiembla. El secretario agarra mis documentos y se los entrega al cónsul, que ya estaba vestido para irse. El cónsul mira de arriba a abajo los papeles, lee la palabra "Posadas", y sin preguntarme nada dice: "Si, si", y se va. El secretario no pregunta nada, me da un enorme libro donde yo tengo que firmar y poner mis huellas digitales. Yo me quedo parada, sin abrir la boca... No entiendo qué es lo que está pasando; no puedo imaginar que finalmente tenga la visa. Alli el secretario me dice: "Ud. tiene suerte, ya tiene la visa". En el hotel hubo mucha alegría, pensando que mi caso era un buen comienzo. Pero desgraciadamente nadie obtuvo visa después de la mía. Es muy triste ver la situación. Todavía faltan cuatro días para la partida, y la gente dice "quizás, quizás ... quizás tengamos suerte ... Quizás alguien consiga una visa..." Salimos con el barco Asturias. Nos informaron que el barco va a llegar a Buenos Aires el 20 de septiembre. Cómo me gustaría ya haber salido...

Una coda a esta parte de la historia: en abril de 2005, un conocido periodista que había publicado varios libros sobre el Nazismo en Argentina y en otras partes, escribió al Ministro de Relaciones Exteriores de Argentina:

En aplicación de la inhumana "Circular 11" emanada de Cancillería en 1938, mi abuelo Santos Goñi, cónsul argentino en el exterior durante la Segunda Guerra, denegó visados a judíos que huían del Holocausto, condenando a muchos a una segura muerte en esos años terribles.

La inminencia del $60^{\circ}$ aniversario del fin de la Segunda Guerra, este 8 de mayo, me mueve a renovar el pedido de derogación como mínimo gesto de reparación por todas las muertes resultantes de la aplicación de la "Circular 11" por mi abuelo y tantos otros funcionarios de aquella Cancillería.

En junio de 2005, la "Circular 11" fue derogada. Uki Goñi habló en la ceremonia de esta derogación:

La existencia de esta orden que aquí hoy se deroga ha representado para mí un secreto de estado que con el paso del tiempo se convirtió en un secreto de familia. Esto es así porque entre los muchos diplomáticos argentinos que debieron aplicarla, estaba mi abuelo Santos Goñi, lo cual nos convirtió a sus descendientes en custodios totalmente involuntarios de un hecho abominable que hasta el día de hoy no figuraba en los libros de nuestra historia.

La historia de nuestro país ha estado plagada de convenientes silencios que permitieron la construcción de una "historia oficial" que excluía datos molestos tales como la existencia de esta circular. Así, la historia para los argentinos se convirtió en un territorio en el cual la verdad y la mentira se hicieron intercambiables.

...no es demasiado difícil intuir una muy cruel y anti-humana línea entre la mano que redactó esta "Circular 11" y las manos que redactaron las órdenes secretas de nuestra dictadura que tanto nos han costado. (http://ukinet.com/circular.htm) 
Volvamos a la historia: en febrero de 1944, Argentina rompió relaciones diplomáticas con Alemania, y le declaró la guerra en marzo de 1945, cuando el final se avecinaba. El estado argentino confiscó las "propiedades alemanas". En Eldorado, esto significó el cierre de las escuelas alemanas y las propiedades de los ciudadanos alemanes que volvieron a Alemania. El estado argentino quitó a los comerciantes alemanes el derecho a vender nafta. Los alemanes debían pedir permiso para salir del pueblo. En 1956, la escuela alemana fue autorizada a reabrir y fue desarrollándose poco a poco una nueva forma de vida "normal".

Para terminar la historia, debo decir que hay muchas historias familiares y locales de la comunidad. Generalmente se dedican a alabar la dureza y el trabajo difícil de los pioneros, el heroísmo de sus mujeres que tenían que cuidar a sus familias en situaciones tan duras, sin acceso a productos de mercado, aisladas y desconectadas "del mundo". Las historias hablan mucho del primer período, a veces también hablan de la vida "normal" del tercer período. Sobre el período del medio, sobre la guerra, hablar es tabú. Como si ese período intermedio fuera un hueco, los colonos guardan silencio, o tratan de olvidar...

$$
* * *
$$

Ésta es la historia. Hay varias cuestiones que surgen a partir de ella. Voy a mencionar algunas:

1. Un tema refiere a la escala y el nivel de análisis. Ésta es una historia de "enraizamientos" y de "encarnaciones" (embodiment and embeddedness). Se trata de la historia mundial, hecha cuerpo en la experiencia real de personas concretas. Individualizadas, enraizadas en lugares y sistemas sociales específicos, como lo indican los casos de M. y de Uki Goñi. Al mismo tiempo, estas experiencias concretas están atravesadas por fuerzas globales, parte del drama humano global. Yo elegí la escala de mi análisis, mi foco. Esto significó usar una lupa histórica, para agrandar el objeto de una cifra en las estadísticas demográficas de los flujos migratorios a sujetos individualizados, tratando de acercarme a algunos de ellos.

Hay también una elección de escala temporal, en este caso la convergencia específica y única de un tiempo biográfico de la vida de la gente y la línea temporal de la historia en que se desenvuelve esa vida. Treinta años es un lapso muy pequeño para muchas disciplinas; es un lapso "largo" en las ciencias sociales contemporáneas, donde los procesos estudiados tienen una dimensión biográfica.

La relación entre biografía e historia es crucial en esto. En un libro ya clásico, La imaginación sociológica de C. Wright Mills, publicado en 1959, el autor ubica su preocupación en el punto en que la historia y la biografía convergen, o en sus palabras, en el lugar donde ocurre la combinación entre las "preocupaciones personales del ambiente" y "las cuestiones públicas de la estructura social" que trascienden los ambientes locales del individuo y el campo de su vida interna. Sostiene que "ningún estudio social que no penetre en los problemas de la biografía, la historia y sus intersecciones en una sociedad ha completado su tarea intelectual" (p.6). Tomo esto como parte de la agenda política expresada en el párrafo final del libro: "Dentro de este rango (la biografía, la historia y sus intrincadas relaciones), se produce la vida del individuo y la construcción de sociedades; es dentro de este rango que la imaginación sociológica tiene la posibilidad de hacer alguna diferencia en la calidad de la vida humana de nuestro tiempo".

2. La segunda cuestión se deriva de la primera. ¿Podemos aplicar a nosotro/as mismo/as el mismo principio de focalizar el lente en la convergencia entre biografía e historia para comprender la realidad de sujetos históricamente localizados? ¿Se puede ganar algo al mirarnos como investigadore/as e intelectuales como sujetos históricamente localizados que tenemos "problemas personales" (o pesadillas intelectuales o académicas) que deben ser conectadas con las "cuestiones públicas de la estructura social" en que vivimos y actuamos?

Pocas veces reflexionamos sobre los caminos personales que nos llevan a nuestras preguntas o temas de investigación. El ritual académico llama a dar razones "científicas", señalando huecos en el conocimiento, o controversias sobre explicaciones o paradigmas teóricos -siempre una justificación anclada en el avance del conocimiento en disciplinas académicas. Y casi siempre quedan en el más absoluto silencio nuestras pasiones o experiencias personales, nuestras orientaciones ideológicas o compromisos políticos. Éstos quedan ocultos y omitidos, como si lo/as investigadore/as fuéramos máquinas del conocimiento perfectas, sin sentimientos ni pasiones.

Sabemos, sin embargo, que toda pregunta tiene una dimensión autobiográfica. Hay algo en nuestras vidas que nos empuja a explorar ciertos temas y no otros. "Toda teoría tiene algo de biografía". Es una mezcla de sentimientos, sensibilidades y experiencias personales, unidos al conocimiento y a los saberes colectivos acumulados. El silencio sobre éstos sólo se suele romper en la vejez, cuando los "hombres de ciencia" escriben sus memorias y autobiografías, o después, cuando los escritores de biografías intentan encontrar al GRAN HOMBRE detrás de las ideas.

¿Por qué este silencio? ¿Cómo incorporarnos a nosotro/ as mismo/as en las historias que contamos y en las explicaciones que damos? En este punto, hay mucho para retomar de la crítica feminista a la división entre la vida privada y el ámbito público, entre razón y emoción (Haraway, 1988). Porque la división o cisura ha estado tan incorporada y enraizada en nuestro pensamiento que se nos aparece como un "apartheid" NATURAL. ¿Existen 
otras maneras de elaborar paradigmas del conocimiento?

3. De modo que voy a concluir con otro relato o narrativa, mucho más personal. Mi pregunta básica es ¿cómo llegué a trabajar sobre este tema? ¿Qué es lo que me llevó en esta dirección? Este "proyecto" -si se lo puede así llamarno estaba en mis planes de trabajo para realizar en Berlín. El tema estaba en algún lugar de mi persona, pero no era un tema para explorar aquí y ahora.

Dos semanas después de llegar a Berlín, cuando mis esfuerzos centrales estaban dedicados a comprender y adaptarme a los rituales y normas del Wissenschaftskolleg, mi hijo Pablo (vive en Londres) me visitó por un cortísimo fin de semana. Compartimos el interés por la fotografía. Hoy en día esto significa mirar pantallas de computadoras más que los ya anticuados álbumes de fotos. Le conté que antes de venir a Berlín digitalicé un buen número de viejas fotos de familia, de las que estaban en las cajas de mamá y papá, y que las traje conmigo a Berlín con la ilusión de que iba a tener tiempo para empezar a ordenarlas. Allí Pablo me preguntó si había alguna foto de Eldorado, a lo que le contesté "Sí, hay unas pocas, no muy buenas. Vamos a tener que trabajar sobre ellas, quizás juntos vos y yo, para hacerlas más visibles y nítidas".

Al día siguiente, en la mesa del almuerzo, alguien mencionó que había un artículo sobre la emigración alemana a la Argentina en el Frankfurter Allgemeine Zeitung. Durante el almuerzo, hablamos sobre la historia de esa emigración. Hablamos sobre las restricciones al ingreso que Argentina puso a los judíos que escapaban (también a los exiliados de la Guerra Civil española), y hablamos sobre los Nazis que llegaron a Argentina después de la guerra, comparando la situación con los que se fueron a Namibia. Después del almuerzo, busqué el diario y encontré el artículo, Buenos Aires war kein Sehn/suchts/ort ("Buenos Aires no era un lugar para anhelar"). Se refería a la inauguración de una exposición especial en el Museo de la Emigración de Bremerhaven (Bremenhaven Auswanderer Haus) sobre "Una vida en Buenos Aires: emigrantes y refugiados alemanes durante el siglo veinte". Para mi gran sorpresa y de manera totalmente inesperada, me encontré leyendo el siguiente párrafo:

Desde hace mucho, el flujo permanente de inmigrantes alemanes en Estados Unidos bloqueó nuestra mirada sobre Argentina como país de inmigración. ... Sólo desde comienzos de la década de 1920 fue que decenas de miles de inmigrantes alemanes buscaron su fortuna estableciendo colonias agrícolas en las provincias, en lugares que hasta entonces habian pertenecido solamente a los indios, con nombres exóticos como "Colonia Liebig" y "Colonia Eldorado". La exposición muestra fotos de jóvenes usando Lederhosen y polainas, plantando retoños de yerba, planta usada para hacer mate, que era la fuente más importante de ingresos (Frankfurter Allgemeine Zeitung, enero 28, 2008: 40).
En sólo 24 horas me había encontrado con Eldorado dos veces, en una pregunta de familia y en el discurso público. No recuerdo cuándo antes me había encontrado con preguntas sobre el lugar, quizás hace 10 o 15 años. ¿Qué hacer? La primera cosa fue ir a visitar el museo y la exposición. Son más de tres horas de tren desde Berlín, pero había que hacerlo. El museo es único, muy interesante. Saqué mucho de la visita, pero nada muy específico sobre Eldorado (el museo vende yerba, pero es de Colonia Liebig y no de Eldorado). En el viaje de regreso, mientras el tren se había detenido (por más de una hora, en medio del camino) para demostrarnos que la puntualidad alemana no es infalible, mi compañera de visita al museo, Bárbara Goebel -directora del Instituto Iberoamericano de Berlín-, me preguntó si quería que en el Instituto alguien busque los materiales que podían tener sobre Eldorado. Yo nunca había pensado en algo así, no tomé la oferta muy en serio porque no estaba en mis planes; Bárbara lo tomó más en serio, y en febrero y marzo buscaron en los archivos...

Eldorado era un capítulo de mi infancia y de mi historia familiar sobre el que yo sabía muy poco. Y hasta ese momento, nunca había tenido mucho interés en explorar el tema y saber más sobre él. Durante los meses siguientes, en la medida en que me adentré en el asunto, me di cuenta que la historia tocaba mis sentimientos más profundos... Al mismo tiempo, era la historia del mundo... Le escribí a Charly Reboratti, geógrafo amigo, pidiéndole referencias bibliográficas. Además de darme algunas, su respuesta fue una pregunta que contribuía a mi inquietud: “¿No se le podría ocurrir a una familia judía otro lugar mas acogedor que Eldorado, cuyos habitantes querían separarse de la Argentina para hacer una republica nazi?" Por supuesto, una respuesta así elevó mi interés y mi compromiso. Tenía que hacer algo... El sentido común y las memorias de historias familiares no ayudaban a explicar lo inexplicable, los enigmas de la vida personal/política.

Allí usé todas mis redes para conseguir información y buscar fuentes. Viajé a Buenos Aires y revolví los desorganizados paquetes de papeles familiares. Encontré los pasaportes polacos de papá y mamá con todos los sellos e inscripciones; entrevisté a una prima que quizás podía contarme algo (hay otras primas que tendré que entrevistar en el futuro). Elegí tres series de cartas que papá y mamá se escribieron entre sí, en Yiddish, las digitalicé y las traje a Berlín. Me sumergí en la lectura de las cartas. No puedo decir cómo, pero mis tempranos años de estudio en la escuela judía retornaron y con la ayuda de un diccionario, pude leer las cartas. La lectura no fue fácil. Es muy difícil participar en los sentimientos de los otros y las otras -la soledad de papá, la expresión de cuánto extrañaba. Pero lo más duro es la sensación de verme como una voyeur, invadiendo una intimidad que no es la mía, confrontando expresiones de sentimientos personales dirigidos a la otra persona solamente, no a mi. Sentí que se me planteaban dilemas éticos en este tipo de invasión. Tenía que convencerme que la gente a 
la que estaba espiando estaban muertos hace tiempo, y que habían dejado todas esas cartas y fotos como legado a sus hijo/as, o sea a mi, a mis hermanas y a mi hermano.

Misterios, enigmas, viejos y nuevos. De a ratos puedo ser irónica, hablar sobre historias "romatizadas", sobre silencios que encarnan relaciones de clase, de género, de raza. Otras veces, la ironía está más allá de mis posibilidades, y las emociones me invaden. ¿Por qué fueron a Eldorado? ¿Por qué se quedaron allí durante el período Nazi? Mi cuerpo tiembla -como el cuerpo de mamá en el consulado argentino en Varsovia-cuando pienso que en el mismo momento en que estaban (estábamos) viviendo en Eldorado rodeados de símbolos y marchas nazis, le llegaban a mis padres las noticias sobre la aniquilación de la familia en Europa.

1. Un tema relacionado tiene que ver con el proceso de producción del conocimiento. Cuando relato la historia de este pequeño proyecto, tengo que incluir a mi hijo, a mi hermana Sara y a Mauricio, a Bárbara y al personal del Ibero, a Christine quien fue la que me trajo la inquietud que desencadenó mi viaje al museo, a Charly que hizo esa pregunta insidiosa, a Delia que viajó a Eldorado y fotocopió materiales en el Museo, a Mark que me ayudó con los mapas, al personal de la biblioteca y de los servicios de computación del WIKO. Y a mucha otra gente, que participó en mis pesadillas y que ayudó a buscar fuentes y referencias. Cada uno y cada una ofrecieron algo, contribuyendo así al producto final. ¿Cómo identificamos los individual y lo colectivo? A la larga, todo conocimiento es social. Como decía Maurice Halbwachs en relación con la memoria, "nunca estamos solos". Es casi seguro que sin todo/as ello/as no se me hubiera ocurrido meterme en esto. De modo que mi pregunta es acerca del YO y el NOSOTRO/AS en el proceso de producción de conocimientos. La propiedad intelectual y la práctica académica se basan en una noción de "propiedad" de las ideas y en una noción de "autoría". ¿Cuál es el lugar del "nosotro/as" en el trabajo intelectual? ¿Hay algún lugar para lo/as "otro/as" en los procesos de aprendizaje?

2. Aquí termino! Elegí no mostrar ninguna foto de familia, quizás inspirada en Roland Barthes, que escribió un libro entero basándose en una fotografía de su madre que no comparte con sus lectores. De todos modos, quiero terminar con algo sobre las fotografías. En uno de sus ensayos sobre la fotografía, John Berger hace la distinción entre dos usos de la fotografía -un uso como experiencia privada (a la que pertenecen las fotos de familia) y un uso público. En el primer caso, dice Berger, la foto se mantiene rodeada del significado del cual fue tomado, contribuyendo así a una memoria viva, a un recuerdo de una vida que fue vivida. En el segundo caso (el caso extremo es la foto publicitaria), la imagen ofrece información, pero es una información desconectada de la experiencia vivida, una fotografía de "extraños", un objeto muerto separado violentamente de su contexto. Cito a Berger,

Las fotografías son reliquias del pasado, huellas de lo que ocurrió. Si los vivos se hacen cargo del pasado, si el pasado se torna una parte integral del proceso en el que la gente hace su propia historia, en ese caso todas las fotografías podrían recuperar un contexto vivo, continuarían existiendo en el tiempo en vez de ser momentos detenidos o arrestados. Quizás sea posible ver a la fotografía como la profecía de una memoria humana que debe ser alcanzada social y políticamente... La tarea de esta fotografía alternativa es incorporarla a la memoria social y política, en vez de usarla como sustituto que promueve la atrofia de cualquier memoria de ese tipo (Berger 1980:57-58).

Berlín, junio de 2008; Buenos Aires, agosto de 2008

\section{Agradecimientos}

Este trabajo fue elaborado durante mi estadía en el Wissenschaftskolleg zu Berlin, en la primera mitad de 2008. Agradezco al WIKO y a mis colegas el estímulo a la búsqueda de nuevas maneras de pensar, expresar y transmitir.

\section{Bibliografía}

Arenhardt de Romagosa, E. H. 2003. "Don Adolfo Schwelm y su proyecto colonizador". III Jornadas sobre Poblamiento, colonización e inmigración en Misiones. Posadas: Ediciones Montoya.

Arenhardt de Romagosa, E. H. 2005. "El sistema 'Wandhufendorf' organiza el paisaje rural de Colonia Eldorado (1924-1948)". IV Jornadas sobre Poblamiento, colonización e inmigración en Misiones. Posadas: Ediciones Montoya.

Berger, J. 1980. About looking. Nueva York: Pantheon Books.

Cooper, F. J. 1986. "Where you go -l go." Inglaterra: edición del autor.

Eidt, R. C. 1971. Pioneer settlement in Northeast Argentina. Madison: University of Wisconsin Press.

Haraway, D. 1988. "Situated Knowledges: The Science Question in Feminism and the Privilege of Partial Perspectives," in Feminist Studies, pp. 575-599.

Hirsch, M. 1997. Family frames : photography, narrative and postmemory. Cambridge : Harvard University Press.

Micolis, D. 1973. Une Communauté Allemande en Argentine: Eldorado. Quebec : Centre International de Recherches sur le Bilinguisme.

Mills, C. W. 1959. The Sociological Imagination. New York: Oxford University Press.

Rizzo, A. 1987. Historia de Eldorado. Eldorado: Municipalidad de Eldorado Misiones. 